\title{
UMA NOVA CONFIGURAÇÃO FAMILIAR: O FENÔMENO "NINHO CHEIO” E SUAS VICISSITUDES
}

\author{
Mariele Rambo \\ Cristina Eloísa Hentges \\ Fernanda Griebler Löeblein \\ Letícia Blum Pando \\ Márcia Inês Bremm Klockner \\ Lao Tsé Maria Bertoldo \\ (Sociedade Educacional Três de Maio - SETREM - RS)
}

\begin{abstract}
Resumo
O presente artigo abordará uma nova configuração familiar: o fenômeno "ninho cheio", denominação dada aos jovens de 25 a 35 anos que permanecem residindo com os pais. Esse estudo foi desenvolvido a partir do método assistemático, utilizando-se de pesquisa bibliográfica, com base em material já elaborado em livros e artigos científicos. Vê-se, a partir da escrita, que este fenômeno é influenciado pelo competitivo mercado de trabalho, pela relação com as figuras parentais e questões emocionais. Observa-se que a dinâmica familiar é um fator relevante que pode facilitar ou dificultar a independência do filho e prolongar a saída da casa dos pais. Neste sentido, as justificativas para esse fenômeno são de caráter multidimensional, envolvendo questões financeiras, culturais, sociais e psicoemocionais.
\end{abstract}

Palavras-chave: Configuração familiar; Ninho cheio; Relações familiares; Mercado de trabalho.

\section{Abstract \\ A new familiar configuration: the "full nest" phenomenon and its vicissitudes}

The present article will speak about a new familiar configuration: the "full nest" phenomenon, denomination given to young people between 25 and 35 years old who remain with their relatives. This study was developed using the unsystematic method and bibliographical research, based on material already elaborated in books and scientific articles. It is seen, from writing, that this phenomenon is influenced by the competitive work market, by the relation with parental figures and emotional issues. It is observed that family dynamics is a relevant factor that can facilitate or hinder the children independence and to prolong the exit of the parent's home. In this sense, the justifications for this phenomenon are multidimensional, involve financial, cultural, social and psycho-emotional issues.

Keywords: Family configuration; Full nest; Family relationships; Work market. 


\section{Introdução}

O presente artigo pretende abordar o fenômeno conhecido como "ninho cheio", as relações pais e filhos que se constituem a partir daí, bem como as novas configurações familiares decorrentes da fase dos jovens adultos. Tem-se como objetivos abordar o que é o ninho cheio, relacionando-o ao termo de "Geração Canguru", evidenciando, ainda, o porquê desses jovens permanecerem em suas famílias de origem. Tem-se por hipóteses as questões afetivas, o enfrentar o desafio de adentrar o mundo adulto, tornando-se financeiramente independente, casando e gerando filhos, o medo e insegurança diante desta independência, a comodidade do ficar na família de origem, as exigências do mercado de trabalho, e como os pais os criaram e trabalharam a questão de independência.

Atualmente, a convivência familiar se prolonga com a permanência de filhos adultos na casa de seus pais, este fenômeno é conhecido como "ninho cheio", termo ainda recente na literatura, traz o outro lado do conhecido "ninho vazio" comum na psicologia como "síndrome do ninho vazio", como apontam Carter e McGoldrick (1995) e Silveira e Wagner (2006). O ninho cheio estabelece um novo desafio para os profissionais da psicologia: pensar as relações e a individualidade dentro deste contexto de organização familiar, ainda, implica em compreender e questionar a fragilidade dos laços afetivos, frente a um cenário social onde predomina o individualismo.

Faz-se relevante embasar este artigo com dados da realidade brasileira. Segundo estes, $81 \%$ das famílias paulistanas ainda possuem pelo menos um filho adulto jovem em casa (Cerveny \& Berthoud, 1997, citado em Silveira \& Wagner, 2006). Na Espanha, $67 \%$ dos rapazes e $49 \%$ das moças de faixa etária entre 25 e 27 anos ainda permanecem vivendo na casa de seus pais (Palacios \& Rodrigo, 1998). Dessa maneira, alguns estudiosos apontam para o surgimento de uma nova fase no ciclo evolutivo da família, sendo esta a etapa do "ninho cheio" (Carter \& McGoldrick, 1995)

Nesta perspectiva, é pertinente uma investigação sobre esta temática, uma vez que é de fundamental importância trabalhar estas novas configurações familiares e o que elas representam na vida dos sujeitos. Não cabe aqui discutir se permanecer em casa está correto ou não, mas investigar os significados envolvidos neste fenômeno para o sujeito e sua família, observando a forma com que gerenciam esta relação, visto que é relevante observar se há uma abertura de conversa diante de situações adversas; se esta permanência parte de um 
querer deste sujeito, ou de uma necessidade de assumir a responsabilidade pelos pais decorrentes de uma patologia; ou de crenças e mitos.

\section{Método}

O presente trabalho trata-se de um estudo exploratório realizado a partir de uma pesquisa bibliográfica (Gil, 2008). Para Gil (2008), a pesquisa bibliográfica desenvolve-se com base em materiais já elaborados, constituindo-se, principalmente, de livros e artigos científicos. Embora em quase todos os estudos seja exigido algum tipo de trabalho dessa natureza, há pesquisas desenvolvidas exclusivamente a partir de fontes bibliográficas.

Realizou-se, assim, uma revisão assistemática da literatura em torno da temática nas seguintes bases de dados: LILACS, Index Psicología - Periódicos Técnico-Científicos, Index Psicología Teses e Scielo. Diante da dificuldade de encontrar artigos que abrangem a temática proposta, surge a necessidade de se pesquisar no Google Acadêmico. Neste, foram encontrados uma série de artigos, e apenas três foram selecionados após a leitura dos resumos, além de uma dissertação de Mestrado. Foram encontrados, ainda, livros que embasam a escrita deste artigo.

\section{Resultados}

A temática do prolongamento da convivência familiar vem despertando interesse da mídia e de pesquisadores, na medida em que este fenômeno representa uma tendência que vem crescendo em diversos países. Muitas denominações têm sido utilizadas para referir-se aos adultos que permanecem com os pais: geração canguru (Henriques, 2004); fenômeno do ninho cheio (Silveira \& Wagner, 2006). O perfil do filho canguru, segundo Costa (2006; citado em Figueiredo, 2008, p. 56), diz respeito ao "jovem na faixa etária entre 25 e 35 anos, com condições econômicas para ter sua própria vida, mas que prefere prolongar a permanência na casa dos pais". Estes adultos vêm chamando a atenção da população e provocando diferentes opiniões, desde a ideia de conforto e acomodação até a percepção de incômodo devido à dependência dos pais (Gallagher, 2013).

Existem vários fatores, como o aumento do tempo de escolarização e difícil inserção no mercado de trabalho, que influenciam na permanência do jovem adulto na casa dos pais. No entanto, segundo Figueiredo (2008), tem sido avaliada a possibilidade da escolha do próprio filho em continuar morando com sua família de origem, mesmo com a 
independência financeira atingida

(Camarano et al, 2004; Henriques, 2004;

Silveira \& Wagner, 2004). Essa escolha que

vai caracterizar o termo "geração canguru".

Paralelamente a isto, Billari (2001)

assevera que, diferentemente das sociedades tradicionais, que incentivaram e valorizavam ritos de passagem como a saída da escola, entrada no mundo do trabalho, casamento, saída da família de origem para a vida adulta, as sociedades contemporâneas não os estimulam. De acordo com Iedema, Becker e Sanders (1997), a modernização das últimas décadas vem oferecendo condições propícias para um estilo de vida em que cada sujeito traça sua trajetória de vida individualmente.

\section{$O$ mercado de trabalho como influência} para a permanência do jovem

Rota (1993; citado em Gallagher, 2013) afirma que "a protelação do jovem na vida adulta é uma consequiência da ausência de garantias de subsistência do mercado aos jovens profissionais. Assim, as questões financeiras dificultam a saída do jovem da casa dos pais".

Leitão (1996) segue a mesma linha de raciocínio ao afirmar que a crise econômica das sociedades retarda a independência financeira do jovem. As famílias com melhores condições financeiras favorecem o sustento mais prolongado do jovem, facilitando que este busque preparar-se para o competitivo mercado de trabalho. Neste processo, os jovens prolongam suas vidas de estudante e permanecem dependentes dos pais.

Concomitantemente a isto, existe um desamparo do sujeito contemporâneo no contexto mutável em que insere-se, ressaltando a tendência competitiva dos tempos atuais Lipovetsky (2004). O sujeito convive com a obrigação do movimento no cenário competitivo e instável da hipermodernidade e não encontra no outro amparo e suporte para a solidão.

$\mathrm{Na}$ hipermodernidade de Lipovetsky (2004) prevalece o medo do futuro devido à impermanência dos nossos tempos. Com a precarização do emprego e o desemprego persistente atualmente, o sujeito convive com a insegurança profissional e material, além do medo da desvalorização dos diplomas e a degradação da vida social. Assim, os jovens temem não encontrar um bom lugar no mercado de trabalho.

Além disso, é comum os filhos "cangurus" buscarem salários condizentes com seus títulos e especializações, não se contentando com o primeiro emprego que lhes ofereça independência, visto que desejam, muitas vezes, uma renda que possa lhes proporcionar um padrão de vida 
semelhante ao que tinham na casa dos pais. Por outro lado, podem acomodar-se pelo quadro de abundância que desfrutam em suas casas (Figueiredo, 2008).

Assim, pode-se pensar o trabalho para o jovem como uma identidade profissional, é onde este sujeito pode desenvolver suas habilidades e ser reconhecido financeiramente por isso. Neste aspecto ainda se reflete o grau de participação escolar do sujeito, uma vez que a escola é base para ingressar em uma carreira profissional de forma mais segura,

\section{[...] também pode-se pensar que} alguns dos aspectos que levam os jovens a adiar a saída da casa dos pais sejam, consequentemente, o prolongamento dos estudos, a difícil inserção e a insegurança no mercado de trabalho atual (Vieira \& Rava, 2012, p. 2).

Henriques (2009), ao corroborar com a ideia, afirma que, ao penetrar numa sociedade que não oferece proteção, a segurança do sujeito é afetada. A autora destaca que o prolongamento da convivência familiar poderia significar uma atitude de não-enfrentamento desta sensação de insegurança que o afeta. Desta forma, a família poderia representar um lugar de confiança, bem como valores aos quais é difícil renunciar frente a uma sociedade que carece de referências tradicionais e estáveis. A família ocuparia, assim, o lugar de refúgio e estaria atrelada ao campo do afeto e do acolhimento.

O papel dos pais e suas consequências emocionais

Mediante a insegurança que os filhos apresentam em sair da casa dos pais, faz-se relevante atentar-se ao papel que estes pais desempenham frente às escolhas de seus filhos, entre elas a escolha de permanecer ou não no mesmo lar, e quais as consequências emocionais imbricadas à este fenômeno.

Sendo assim, o processo de separação entre pais e filhos afeta a família, pois ela passa a experienciar sentimentos novos ou diferentes e a perceber sentidos diferenciados na configuração familiar (Henriques, 2009). No entanto, essa experiência é importante para a individuação dos filhos.

Nesta perspectiva, o ambiente familiar pode facilitar ou dificultar a saída dos filhos da casa da família de origem, tendo um papel relevante no processo de aquisição de independência destes. Bowlby (2004) também ressalta a importância de que os pais estimulem gradual e constantemente a autonomia dos filhos. Entretanto, deve ser estabelecido o apego seguro entre os mesmos, uma vez que, 
quando o indivíduo está seguro de poder contar e confiar em alguém em caso de necessidade, este se torna mais capaz de melhor exercitar seus talentos. Em contraste, o estabelecimento do apego inseguro na infância pode amedrontar o adulto frente ao desafio da construção da vida sem a interferência dos pais.

Aberastury e Knobel (1970), colocam do papel fundamental dos pais no processo de independência de seus filhos, bem como a importância da elaboração do luto da perda da infância, visto que facilitaria a entrada destes na vida adulta. Com a elaboração do luto dos pais, o jovem percebe que a separação se faz necessária para que ocorra uma individuação. Porém, destaca-se que esta individuação e independência, também devem possuir espaço dentro do próprio lar, havendo ressignificação dos papéis parentais, trazendo uma nova dinâmica familiar e consciência da individuação dos membros da família, segundo a perspectiva de Henriques (2009).

"Outro fator que pode motivar o prolongamento da permanência dos adultos jovens no lar parental pode estar relacionado com o fluxo das ansiedades, tanto no âmbito dos estressores verticais como no dos horizontais" (Vieira \& Rava, 2012, p. 85), visto que estressores verticais, segundo Carter e McGoldrick (1995) e
Falcke e Wagner (2005), abordam conceitos sobre padrões, mitos, lealdades, ritos e legados familiares, e consideram que

[...] a lealdade não é uma lei manifesta mas um laço invisivel que une a família. Os mitos são os sistemas de crenças de cada família, e os legados referem-se às informações definidas pela família para serem passadas de uma geração a outra. Os estressores verticais podem ser predizíveis ou não; os prediziveis são os desenvolvimentais, as etapas do ciclo vital, como a transição da adolescência para a vida; os impredizíveis são a morte de um familiar, nascimento, doença crônica, acidentes, entre outros (Vieira \& Rava, 2012, p. 86).

Talvez seja pertinente a reflexão sobre a importância dos estressores verticais e horizontais no fenômeno estudado. Assim sendo, a lealdade em algumas famílias pode ser observada por meio dos sentimentos exacerbados dos filhos para com a família de origem, e, dessa forma, estes podem permanecer em casa por mais tempo, podendo ainda cumprir com as expectativas de seus pais quanto ao seu futuro (Vieira \& Rava, 2012).

Os estressores horizontais, como a passagem da adolescência para a vida adulta, também podem gerar ansiedade na 
família, já que, segundo Carter e McGoldrick (1995), essas transições estão "constantemente sujeitas aos estresses na rede familiar". A ansiedade normal da partida ou não do filho de casa, quando somada às ansiedades trazidas pela família ao longo dos anos ou agravada por um fator externo, como uma crise financeira, poderia resultar na permanência do adulto jovem no lar parental.

No que diz respeito às consequências emocionais do fenômeno "ninho cheio", para os filhos adultos, pesquisadores da área concordam que há a falta de uma autonomia adequada que os mesmos possam apresentar, influenciando, destarte, em um sentimento de desorientação e de dependência emocional por parte destes filhos (Jablonski, 2005; Silveira, 2004; Henriques, 2003; Pais, 2003; Lopes, 1999, citados em Figueiredo, 2008).

Segundo Demetrio (2012), os jovens enfrentam dificuldades para ter uma vida independente quando saem da casa dos pais. Os homens solteiros, aliás, que saem da casa dos pais, apresentam dificuldades de se planejar para comprar itens como meias ou escovas de dente. Assim, ao emancipar-se dos pais, é comum que os filhos consideram problemática a organização doméstica, gerando consequentemente, este sentimento de desorientação.
Contudo, a posição dos pais é de fundamental importância na constituição da autonomia de seus filhos, sua individuação, bem como sua independência. Esta nova configuração familiar envolve desafios, visto que a família precisa se organizar para que este fenômeno não traga transtornos, ao mesmo tempo em que, se o filho decidir sair de casa, este processo também ocorra de forma saudável.

A relação com os pais como influência na permanência do jovem

Os pais, assim como podem deixar seus filhos partirem, também podem enredá-los perpetuamente no seio familiar. Nesses casos, a família organiza-se de forma a dificultar a saída de seus filhos de casa em vez de ajudá-los a consolidar seu processo de individuação e construção de uma vida separada e independente (Silveira \& Wagner, 2006), visto que o impacto gerado por uma separação entre pais e filhos, pode ser considerado uma forma de luto, pela perda de fatores que antes eram diariamente vivenciados "em família". Ainda, ressalta-se que o lançamento dos filhos para o mundo adulto, culminando ou não com sua saída de casa, exigirá um reajustamento da conjugalidade do casal. Para os casais que organizam sua relação baseada na criação dos filhos, esta nova fase 
pode ser mais difícil (Mccullough \& Rutenberg, 1995; Ribeiro, 2005).

Pode-se, neste sentido, fazer relação a um contexto histórico da criação dos filhos por esta família, se os pais elaboraram a perda da infância e com o passar da adolescência o amadurecimento do jovem, além de levar em conta se este jovem teve um processo de desidealização das suas figuras parentais. Todos estes fatores são de suma importância, uma vez que facilita o curso normal do desenvolvimento, permitindo que este jovem possa desenvolver relações extrafamiliares (Gallagher, 2013).

Segundo Groisman (2000) a transgeracionalidade pode, ainda, ser um fator importante para a ocorrência do fenômeno "ninho cheio", visto que ela se refere ao fato de as pessoas absorverem os conhecimentos passados pelas figuras significativas do mundo familiar e, através delas, serem influenciadas nas suas decisões. Entretanto, compreende-se que isso só será um fator determinante para a reprodução de comportamentos na família, se a intensidade dessa absorção for acentuada, o que, no caso do fenômeno estudado, parece não ser muito presente.

Ainda neste sentido, Henriques (2009), assevera que as relações cada vez mais igualitárias e saudáveis entre os membros da família podem contribuir para que os filhos adiem a saída da casa dos pais. O diálogo e a cumplicidade podem tornar a convivência entre eles mais confortável e segura. Dessa forma, a saída dos filhos da casa dos pais é dificultada pela proximidade e cumplicidade entre os membros da família.

Como forma de embasar esta discussão, faz-se necessária a inserção de uma pesquisa recente com a população brasileira, a qual revela que os pais têm incentivado a permanência de seus filhos em casa por meio do aumento de regalias, cuidados e concessões, visto que há a permissão para dormir com o namorado no domicílio parental (Wendling e Wagner, 2005), bem como a abertura para os filhos fazerem sexo em casa e uma relação de dependência e confiança mútuas. Os pais então lançam estratégias para melhor convivência, vindo de encontro com as novas necessidades dos filhos, agora adultos (Silveira \& Wagner, 2006).

Concomitantemente a isto, a dificuldade da conquista da independência dos jovens é causada, para Dolto (1989), pelo fato de os pais se colocarem como amigos e parceiros de seus filhos. Os pais que assumem essa posição buscam uma relação na qual há intimidade suficiente para conhecer a vida dos filhos de maneira precisa. 
Os filhos da chamada "geração canguru", comportam-se de maneira diferente de seus pais na juventude, percebe-se a diminuição de conflitos entre gerações, mais abertura para diálogos e negociações entre pais e filhos, rompendo com costumes antigos, onde a maior autoridade era o homem, ou ambos os pais, sem que os filhos tivessem voz nas decisões da família. Além disso, a comodidade oferecida pelo lar dos pais e a maior liberdade neste contexto, são contribuintes para esta permanência (Figueiredo, 2008).

\section{Considerações Finais}

Após o estudo realizado, resultados deste artigo apontam que o fenômeno do "Ninho Cheio" não representa necessariamente um inconveniente para a família, uma vez que muitos pais têm estimulado a permanência de seus filhos. Araújo (2009) ainda destaca que a tendência é que os membros da família busquem estabelecer relações mais democráticas, onde há diálogo, o respeito às diferenças e a divisão de responsabilidades de modo mais igualitário para todos.

O modelo hierárquico presente na história, à medida que, aos poucos, se dissolve, rompe com padrões de estruturação familiar, visto que eventos, como a saída de casa, antes pré-definidos, atualmente possibilitam às famílias maior liberdade de escolha a partir do que se torna conveniente aos sujeitos, suprindo suas necessidades financeiras, biológicas, intelectuais, sociais e psicoemocionais.

Ressalta-se que esta nova dinâmica familiar, de caráter multidimensional, se estabelece por muitos fatores, que vão além da relação entre pais e filhos, mas contexto histórico familiar, as condições do mercado de trabalho, e o desenvolvimento da autonomia do sujeito, abordados no transcorrer do artigo. Para tanto, observar os diversos papeis na família é de suma importância para compreender o fenômeno de forma ampla, uma vez que a visão fidedigna deste dar-se-á a partir da interrelação dos sujeitos, e não de forma isolada (Vieira \& Rava, 2012).

Por fim, vê-se o quanto este tema ainda precisa ser discuto nas Academias e sociedade em geral, visto que há certa escassez de materiais que tratam do tema proposto. As novas configurações familiares estão emergindo, e cabe aos profissionais, imbricados em suas diferentes abordagens e linhas teóricas, atentarem-se aos sujeitos provenientes destas que é o objeto da prática psi. 
MARIELE RAMBO, CRISTINA ELOÍSA HENTGES, FERNANDA GRIEBLER LÖEBLEIN, LETÍCIA BLUM PANDO, MÁRCIA INÊS BREMM KLOCKNER, LAO TSÉ MARIA BERTOLDO

\section{Referências}

Aberastury, A. \& Knobel, M. (1970). Adolescência normal. Porto Alegre: Artes Médicas.

Araújo, M. F. (2009). Gênero e família na construção de relações democráticas. In: FéresCarneiro, T. (Org.). Casal e família: permanências e rupturas. São Paulo: Casa do Psicólogo.

Azambuja, J. E. B. \& Jaeger, F. P. (2015). A conjugalidade em casais de meia-idade. Disciplinarum Scientia; 16 (1); 123-132.

Billari, F. (2001). The analysis of early life courses: complex descriptions of the transition to adulthood. Journal of Population Research, 18, (2), 119-142. DOI 10.1007/BF03031885.

Bowlby, J. (2004). Separação: angústia e Raiva. São Paulo: Martins Fontes.

Caramano, A. A., Pazinato, M. T., Kanso, S. \& Vianna, C. (2003). A transição para a vida adulta: novos ou velhos desafios? Boletim Mercado de Trabalho: Conjuntura e Análise. $21 ; 53-66$.

Carter, B. \& McGoldrick, M. (1995). As mudanças no ciclo de vida familiar: uma estrutura para a terapia familiar. (2 edição). Porto Alegre: Artes Médicas.

Demetrio, A. (2012). De olho nos solteiros, serviço faz entrega agendada de meias e cuecas. O Globo Online G1. Disponível em: <http://g1.globo.com/tecnologia/noticia/2012/05/deolho-nos-solteiros-servicofaz-entrega-agendada-de-meias-e-cuecas.html>.

Dolto, F. (1989). A causa dos adolescentes. Rio de Janeiro: Nova Fronteira.

Figueiredo, M. G. (2008). Ninho cheio, Geração Canguru: A permanência do filho adulto em casa segundo a perspectiva dos pais. Dissertação de Mestrado em Psicologia Clínica Pontifícia Universidade Católica de São Paulo.

Gallagher, I. M. (2013). Geração canguru: entre o conforto e o desamparo. Dissertação (Mestrado) - Pontifícia Universidade Católica do Rio de Janeiro, Departamento de Psicologia.

Gil, A. C. (2008). Como elaborar projetos de pesquisa. (4ª edição). São Paula: Atlas.

Groisman, M. (2000). Família é Deus: descubra como a família define quem você é. Rio de Janeiro: Eldorado, Núcleo Pesquisas.

Henriques, C. R. (2004) "Geração Canguru": o prolongamento da convivência familiar. Dissertação (Mestrado em Psicologia Clínica) - Departamento de Psicologia, Pontifícia Universidade Católica do Rio de Janeiro, Rio de Janeiro.

Iedema, J., Becker, H. A. \& Sanders, K. (1997). Transitions into Independence: A Comparison of Cohorts Born since 1930 in the Netherlands. European Sociological Review. Oxford, 13 (2), 117-137. DOI 10.1093/oxfordjournals.esr.a018208. 
Leitão, C. (1996). O prolongamento da adolescência. Dissertação (Mestrado em Psicologia Clínica) - Departamento de Psicologia, Pontifícia Universidade Católica do Rio de Janeiro, Rio de Janeiro.

Lipovetsky, G. (2004). O império do efêmero: a moda e seu destino nas sociedades modernas. São Paulo: Companhia das Letras.

Mccullough, P. \& Rutenberg, S. (1995). Lançando os filhos e seguindo em frente. In: Carter, B., \& McGoldrick, M. As mudanças no ciclo de vida familiar: uma estrutura para a terapia familiar. Trad. Maria Adriana Veríssimo Veronese. (2a . edição). Porto Alegre: Artes Médicas.

Ribeiro, M. T. M. L. S. R. (2014) Casais de meia-idade: Estudos com casais portugueses numa perspectiva sistêmica. Psicologia, 19 (1-2), 57-85. DOI 10.17575/rpsicol.v19i1/2.398.

Rodrigo, M. J., \& Palácios, J. (1998). Familia y desarrollo humano. Madrid: Alianza.

Silveira, P. G. \& Wagner, P. G. (2006). Ninho cheio: a permanência do adulto jovem em sua família de origem. Estudos de Psicologia. 23 (4); 441-453. DOI 10.1590/S0103$166 \times 2006000400012$.

Vieira, A. C. S. \& Rava, P. G. S. (2010). Ninho cheio: Uma nova etapa do ciclo vital familiar? Barbarói. Santa Cruz do Sul, 33; 118-134.

Vieira, A. C. S. \& Rava, P. G. S. (2012). Ninho cheio: perspectivas de pais e filhos. Psicologia: teoria e prática, 14 (1), 84-96.

Wendling, M. I., \& Wagner, A. (2005). Saindo da casa dos pais: a construção de uma nova identidade familiar. In A. Wagner (Coord.), Como se perpetua a família? A transmissão dos modelos familiares. Porto Alegre: EDIPUCRS.

\section{Os autores:}

Mariele Rambo é acadêmica do curso de Psicologia, da Sociedade Educacional Três de Maio - SETREM. Bolsista integral pelo PROUNI. Voluntária de Iniciação Científica. Secretária da Revista Práxis, do curso de Psicologia da SETREM. E-mail: mari_rambo@ hotmail.com

Cristina Eloísa Hentges é acadêmica do curso de Psicologia da Sociedade Educacional Três de Maio - SETREM. Possui Formação em Coaching e Mentoring pela Retorno Consultoria e Carreira. E-mail: cristinaeloisahentges@hotmail.com

Fernanda Griebler Löeblein é acadêmica do curso de Psicologia da Sociedade Educacional Três de Maio SETREM. E-mail: fergloeblein @ gmail.com

Letícia Blum Pando é acadêmica do curso de Psicologia da Sociedade Educacional Três de Maio - SETREM. Email: leticiabpando@gmail.com

Márcia Inês Bremm Klockner possui graduação em Administração pela Sociedade Educacional Três de Maio, Brasil (1991). E-mail: marciaklockner@yahoo.com.br 
MARIELE RAMBO, CRISTINA ELOÍSA HENTGES, FERNANDA GRIEBLER LÖEBLEIN, LETÍCIA BLUM PANDO, MÁRCIA INÊS BREMM KLOCKNER, LAO TSÉ MARIA BERTOLDO

Lao Tsé Maria Bertoldo possui graduação em Psicologia pela Universidade Regional do Noroeste do Estado do Rio Grande do Sul (2007), Mestrado em Educação Nas Ciências pela Universidade Regional do Noroeste do Estado do Rio Grande do Sul (2010), atualmente está cursando Doutorado em Psicologia Clínica na Universidade do Vale do Rio dos Sinos-UNISINOS. Atua como professora horista da Sociedade Educacional Três de Maio. E-mail: laotsebertoldo@yahoo.com.br

Recebido em: 07/08/2017.

Aprovado em: 29/12/2017. 